\title{
Antibiotic susceptibility profiles of Mycoplasma sp. 1220 strains isolated from geese in Hungary
}

\author{
Dénes Grózner ${ }^{1 \dagger}$, Zsuzsa Kreizinger ${ }^{1 \dagger}$, Kinga M. Sulyok' ${ }^{1}$ Zsuzsanna Rónai ${ }^{2}$, Veronika Hrivnák', Ibolya Turcsányi ${ }^{2}$,
} Szilárd Jánosi ${ }^{2}$ and Miklós Gyuranecz ${ }^{1 *}$

\begin{abstract}
Background: Mycoplasma sp. 1220 can induce inflammation primarily in the genital and respiratory tracts of waterfowl, leading to serious economic losses. Adequate housing and appropriate antibiotic treatment are promoted in the control of the disease. The aim of the present study was to determine the in vitro susceptibility to thirteen different antibiotics and an antibiotic combination of thirty-eight M. sp. 1220 strains isolated from geese and a duck in several parts of Hungary, Central Europe between 2011 and 2015.

Results: High $\mathrm{MIC}_{50}$ values were observed in the cases of tilmicosin $(>64 \mu \mathrm{g} / \mathrm{ml})$, oxytetracycline $(64 \mu \mathrm{g} / \mathrm{ml})$, norfloxacin $(>10 \mu \mathrm{g} / \mathrm{ml})$ and difloxacin $(10 \mu \mathrm{g} / \mathrm{ml})$. The examined strains yielded the same $\mathrm{MIC}_{50}$ values with spectinomycin, tylosin and florfenicol $(8 \mu \mathrm{g} / \mathrm{ml})$, while enrofloxacin $\left(\mathrm{MIC}_{50} 5 \mu \mathrm{g} / \mathrm{ml}\right)$, doxycycline $\left(\mathrm{MIC}_{50} 5 \mu \mathrm{g} / \mathrm{ml}\right)$, lincomycin $\left(\mathrm{MIC}_{50} 4 \mathrm{\mu g} / \mathrm{ml}\right.$ ) and lincomycin-spectinomycin (1:2) combination ( $\mathrm{MIC}_{50} 4 \mathrm{\mu g} / \mathrm{ml}$ ) inhibited the growth of the bacteria with lower concentrations. Tylvalosin $\left(\mathrm{MIC}_{50} 0.5 \mu \mathrm{g} / \mathrm{ml}\right.$ ) and two pleuromutilins (tiamulin $\mathrm{MIC}_{50} 0$. $625 \mu \mathrm{g} / \mathrm{ml}$; valnemulin $\mathrm{MIC}_{50} \leq 0.039 \mu \mathrm{g} / \mathrm{ml}$ ) were found to be the most effective drugs against M. sp. 1220 . However, strains with elevated MIC values were detected for all applied antibiotics.

Conclusions: Valnemulin, tiamulin and tylvalosin were found to be the most effective antibiotics in the study. Increasing resistance was observed in the cases of several antibiotics. The results highlight the importance of testing Mycoplasma species for antibiotic susceptibility before therapy.
\end{abstract}

Keywords: Antibiotic resistance, Duck, Goose, MIC, Microbroth dilution, Mycoplasma sp. 1220

Abbreviations: MIC, Minimal inhibitory concentrations

\section{Background}

Mycoplasma sp. 1220 was first described as a new Mycoplasma species by Stipkovits et al. in 1986 [1]. This Mycoplasma species causes cloaca and phallus inflammation and testicular atrophy in the ganders $[1,2]$. In the infected geese salpingitis and vaginitis are the main symptoms [1, 3]. The egg production activates the pathogen and the flared up mycoplasmosis could induce lethal pathological changes in the embryos $[1,4]$. Airsacculitis and peritonitis are also common, and general

\footnotetext{
* Correspondence: m.gyuranecz@gmail.com

${ }^{\dagger}$ Equal contributors

${ }^{1}$ Institute for Veterinary Medical Research, Centre for Agricultural Research, Hungarian Academy of Sciences, Hungária körút 21, Budapest 1143, Hungary Full list of author information is available at the end of the article
}

symptoms such as changes in thirst, decreased food consumption, body weight losses, weakness, nasal discharge, impaired breathing, conjunctivitis, diarrhoea and nervous signs were also described in the affected waterfowl flocks [2, 5-8]. Mycoplasma infection of the birds can aggravate diseases caused by other agents and could lead to serious economic losses $[3,6]$. Since there is no commercially available vaccine against $M$. sp. 1220, adequate housing and appropriate antibiotic treatment are promoted in the control of the diseases caused by this agent. Prophylactic medication could prevent economic losses if appropriate antibiotics are administered in the early weeks of life and in expected stress periods. Medication of the layers is essential to reduce the vertical transmission of $M$. sp. $1220[2]$. 
Mycoplasmas are resistant to $\beta$-lactam antimicrobials because of the lack of cell-wall and the bacteria are also resistant to membrane synthesis inhibitors [2, 9]. Antibiotics such as quinolones, tetracyclines, macrolides and pleuromutilins which induce DNA fragmentation or inhibition at the level of protein synthesis are the drugs of choice for the therapy of mycoplasmosis. Among the macrolides, erythromycin showed high effectiveness against Mycoplasma strains which could ferment glucose (e.g. M. sp. 1220), while arginine-hydrolysing strains proved to be less susceptible to this compound [2, 10]. Mycoplasma infected waterfowl and poultry flocks are usually treated with macrolides, pleuromutilins or with the combination of lincomycin and spectinomycin [3, 11-18].

The aim of this study was to determine the susceptibility of 38 Hungarian M. sp. 1220 isolates to thirteen antibiotics and a drug combination using the microbroth dilution method.

\section{Methods}

A total of 38 M. sp. 1220 strains isolated from geese and a duck originating from different parts of Hungary were tested in the study (Table 1, Fig. 1). The samples were collected during routine diagnostic examinations or necropsies between 2011 and 2015, thus ethical approval was not required for the study. Phallus lymph, cloaca swabs, tracheal swabs, follicules and lung samples were washed in $2 \mathrm{ml}$ of Mycoplasma broth medium ( $\mathrm{pH} 7.8$ ) (ThermoFisher Scientific Inc./Oxoid Inc./, Waltham, MA) supplemented with $0.5 \%(\mathrm{w} / \mathrm{v})$ sodium pyruvate, $0.5 \%$ $(\mathrm{w} / \mathrm{v})$ glucose and $0.005 \%(\mathrm{w} / \mathrm{v})$ phenol red and incubated at $37{ }^{\circ} \mathrm{C}$ in a $5 \% \mathrm{CO}_{2}$ atmosphere. The cultures were inoculated onto solid Mycoplasma media (Thermo Fisher Scientific Inc./Oxoid Inc./) after colour change of the broth, and were incubated at $37{ }^{\circ} \mathrm{C}$ and $5 \% \mathrm{CO}_{2}$ until visible colonies appeared (1-2 days). Purification of mixed cultures was performed by one-time filter cloning, minimizing the in vitro mutations of the isolates. The QIAamp DNA Mini Kit (Qiagen Inc., Hilden, Germany) was used for DNA extraction according to the manufacturers' instructions for Gram-negative bacteria. The purity of the cultures was confirmed by a universal Mycoplasma PCR system targeting the 16S/23S rRNA intergenic spacer region in Mycoplasmatales followed by sequencing on an ABI Prism 3100 automated DNA sequencer (Applied Biosystems, Foster City, CA), sequence analysis and BLAST search [19]. The number of colour changing units (CCU) was calculated by microbroth dilution method, from the lowest dilution showing colour change after one week of incubation [9].

The following antimicrobial agents were examined during the microbroth dilution tests: the fluoroquinolones: enrofloxacin (batch SZBA336XV), difloxacin (SZBD178XV) and norfloxacin (batch SZBD099XV); the aminoglycoside: spectinomycin (batch SZBB166XV); the lincosamide: lincomycin (batch SZBC340XV); the tetracyclines: doxycycline (batch SZBD007XV) and oxytetracycline (batch SZBC320XV); the macrolides: tilmicosin (batch SZBC345XV) and tylosin (batch SZBB160XV); the pleuromutilins: tiamulin (batch SZBC026XV) and valnemulin (batch SZBE127XV); and the phenicol: florfenicol (batch SZBC223XV); all products originated from VETRANAL, Sigma-Aldrich, Germany. The macrolide tylvalosin (Aivlosin, ECO Animal Health Ltd., UK; LOT M102A) was also included in the examinations. Lincomycin and spectinomycin were applied also in combination at a ratio of 1:2. The antibiotics were diluted and stored according to the recommendations of Hannan [9]. Stock solutions of $1 \mathrm{mg} / \mathrm{ml}$ fluoroquinolones were prepared in $0.1 \mathrm{M} \mathrm{NaOH}$; stock solution of $1 \mathrm{mg} / \mathrm{ml}$ florfenicol was prepared in $96 \%$ ethanol and in sterile distilled water; and the rest of the stock solutions of $1 \mathrm{mg} / \mathrm{ml}$ were prepared in sterile distilled water. Dilutions of the antibiotics were freshly prepared for each microtest from the aliquots stored at $-70{ }^{\circ} \mathrm{C}$. Twofold dilutions were prepared in the range $0.039-10 \mu \mathrm{g} / \mathrm{ml}$ for fluoroquinolones, doxycycline and pleuromutilins, $0.25-64 \mu \mathrm{g} / \mathrm{ml}$ for spectinomycin, lincomycin, lincomycin-spectinomycin (1:2) combination, oxytetracycline and macrolides and $0.125-32 \mu \mathrm{g} / \mathrm{ml}$ for florfenicol.

The microbroth dilution examinations on $10^{4}-10^{5} \mathrm{CCU} /$ $\mathrm{ml}$ of the strains were performed according to Hannan [9]. Mycoplasma broth medium was used in the tests as well, and each 96-well microtiter plates contained growth controls (broth medium without antibiotic), sterility controls (broth medium without antibiotic and Mycoplasma inoculum) and $\mathrm{pH}$ controls (broth medium adjusted to $\mathrm{pH}$ 6.8). One clinical isolate (strain MYCAV 65) was selected to be used as quality control of minimal inhibitory concentration (MIC) determination throughout the experiments. The duplicates of three clinical isolates and the duplicate of the selected strain (MYCAV 65) were tested on each 96well microtiter plates.

The MIC values were determined from the lowest concentration of the antibiotics where no $\mathrm{pH}$ and colour change of the broth was detected after one week of incubation, meaning that the growth of the bacteria was completely inhibited in the broth. $\mathrm{MIC}_{50}$ and $\mathrm{MIC}_{90}$ values were defined as the lowest concentrations that inhibited the growth of $50 \%$ or $90 \%$ of the strains [9].

\section{Results}

The quality control strain (MYCAV 65) showed consistent results throughout the study. Strains with elevated MIC values were found in the cases of all tested antibiotics (Tables 1 and 2).

Among the fluoroquinolones, the MIC values of enrofloxacin and difloxacin showed a wide range (1.25 to 
Table 1 Background data and MIC values of the isolated Mycoplasma sp. 1220 strains

\begin{tabular}{|c|c|c|c|c|c|c|c|c|c|c|}
\hline \multirow[b]{3}{*}{ Sample ID } & \multirow[b]{3}{*}{ Sample source } & \multirow[b]{3}{*}{ Place } & \multirow[b]{3}{*}{ Animal } & \multirow[b]{3}{*}{ Date } & \multicolumn{6}{|c|}{ MIC values $(\mu \mathrm{g} / \mathrm{ml})$} \\
\hline & & & & & \multicolumn{3}{|c|}{ Fluoroquinolones } & \multirow{2}{*}{$\begin{array}{l}\text { Aminoglycoside } \\
\text { Spectinomycin }\end{array}$} & \multirow{2}{*}{$\begin{array}{l}\text { Lincosamide } \\
\text { Lincomycin }\end{array}$} & \multirow[b]{2}{*}{$\begin{array}{l}\text { Lincomycin- } \\
\text { spectinomycin } \\
\text { (1:2) combination }\end{array}$} \\
\hline & & & & & Enrofloxacin & Norfloxacin & Difloxacin & & & \\
\hline MYCAV 65 & Phallus lymph & Rém & goose & 2014 & 5 & $>10$ & 10 & 16 & 4 & 4 \\
\hline MYCAV 34 & Phallus lymph & Szentes & goose & 2011 & 5 & $>10$ & 10 & 8 & 4 & 2 \\
\hline MYCAV 35 & Phallus lymph & Rém & goose & 2012 & 5 & $>10$ & 10 & $>64$ & 4 & 4 \\
\hline MYCAV 36 & Cloaca & Hajdúböszörmény & goose & 2012 & 5 & $>10$ & $>10$ & 64 & 4 & 4 \\
\hline MYCAV 38 & Cloaca & Kelebia & goose & 2012 & 2.5 & $>10$ & 10 & 8 & 2 & 4 \\
\hline MYCAV 44 & Cloaca & Nagykamarás & goose & 2012 & 5 & $>10$ & 10 & 8 & 4 & 4 \\
\hline MYCAV 47 & Lung & Tázlár & duck & 2012 & $>10$ & $>10$ & $>10$ & 16 & $>64$ & 16 \\
\hline MYCAV 49 & Phallus lymph & Tiszavasvári & goose & 2013 & 5 & $>10$ & 10 & 16 & 4 & 4 \\
\hline MYCAV 50 & Phallus lymph & Cered & goose & 2013 & $>10$ & $>10$ & $>10$ & 16 & 4 & 4 \\
\hline MYCAV 51 & Phallus lymph & Derekegyház & goose & 2013 & 5 & $>10$ & 10 & 32 & 4 & 4 \\
\hline MYCAV 53 & Phallus lymph & Szentes & goose & 2013 & 5 & $>10$ & 10 & 16 & 4 & 4 \\
\hline MYCAV 54 & Follicule & Hódmezővásárhely & goose & 2013 & 5 & $>10$ & 10 & 8 & 4 & 4 \\
\hline MYCAV 55 & Follicule & Kiskunmajsa & goose & 2013 & 10 & $>10$ & 10 & 8 & 4 & 4 \\
\hline MYCAV 56 & Phallus lymph & Sükösd & goose & 2013 & 1.25 & $>10$ & 1.25 & 8 & 4 & 4 \\
\hline MYCAV 59 & Follicule & Rém & goose & 2013 & 5 & $>10$ & 10 & 8 & 4 & 4 \\
\hline MYCAV 61 & Phallus lymph & Tatárszentgyörgy & goose & 2013 & 5 & $>10$ & 10 & 16 & 2 & 4 \\
\hline MYCAV 63 & Trachea & Sükösd & goose & 2013 & 1.25 & 10 & 1.25 & 8 & 2 & 2 \\
\hline MYCAV 66 & Phallus lymph & Tiszaföldvár & goose & 2014 & 5 & $>10$ & 10 & 16 & 4 & 4 \\
\hline MYCAV 67 & Phallus lymph & Szentes & goose & 2014 & 5 & $>10$ & 10 & 8 & $>64$ & 16 \\
\hline MYCAV 68 & Phallus lymph & Érpatak & goose & 2014 & 5 & $>10$ & 10 & 8 & $>64$ & 32 \\
\hline MYCAV 69 & Phallus lymph & Ludas & goose & 2014 & 5 & $>10$ & 10 & 4 & 4 & 4 \\
\hline MYCAV 70 & Phallus lymph & Cered & goose & 2014 & $>10$ & $>10$ & $>10$ & 16 & 4 & 4 \\
\hline MYCAV 71 & Phallus lymph & Sükösd & goose & 2014 & 1.25 & $>10$ & 1.25 & 8 & 2 & 4 \\
\hline MYCAV 72 & Phallus lymph & Nagykamarás & goose & 2014 & 5 & $>10$ & 10 & 8 & 4 & 4 \\
\hline MYCAV 75 & Phallus lymph & Dömsöd & goose & 2014 & 5 & $>10$ & 10 & 16 & 4 & 4 \\
\hline MYCAV 76 & Phallus lymph & Tiszabábolna & goose & 2014 & 5 & $>10$ & 10 & 32 & 8 & 4 \\
\hline MYCAV 91 & Phallus lymph & Hajdúsámson & goose & 2011 & 10 & $>10$ & $>10$ & 8 & 8 & 4 \\
\hline MYCAV 93 & Phallus lymph & Bojt & goose & 2014 & 2.5 & $>10$ & 1.25 & 8 & 2 & 4 \\
\hline MYCAV 94 & Cloaca & Tiszabábolna & goose & 2012 & 2.5 & $>10$ & 5 & 16 & 4 & 4 \\
\hline MYCAV 160 & Phallus lymph & Érpatak & goose & 2015 & $>10$ & $>10$ & $>10$ & 16 & 4 & 4 \\
\hline MYCAV 161 & Phallus lymph & Szilaspogony & goose & 2015 & $>10$ & $>10$ & $>10$ & 8 & 4 & 4 \\
\hline MYCAV 162 & Phallus lymph & Encsencs & goose & 2015 & 2.5 & $>10$ & 10 & 8 & 4 & 4 \\
\hline MYCAV 176 & Phallus lymph & Cered & goose & 2015 & 10 & $>10$ & 5 & 8 & 4 & 4 \\
\hline MYCAV 177 & Phallus lymph & Cered & goose & 2015 & $>10$ & $>10$ & 10 & 8 & 4 & 4 \\
\hline MYCAV 178 & Follicule & Cered & goose & 2015 & 5 & $>10$ & 10 & 8 & 2 & 4 \\
\hline MYCAV 179 & Trachea & Apátfalva & goose & 2015 & 10 & $>10$ & 10 & 16 & 4 & 4 \\
\hline MYCAV 180 & Phallus lymph & Kisbér & goose & 2015 & 5 & $>10$ & 10 & $>64$ & 4 & 4 \\
\hline MYCAV 202 & Cloaca & Kelebia & goose & 2015 & 5 & $>10$ & 5 & 16 & 4 & 4 \\
\hline
\end{tabular}




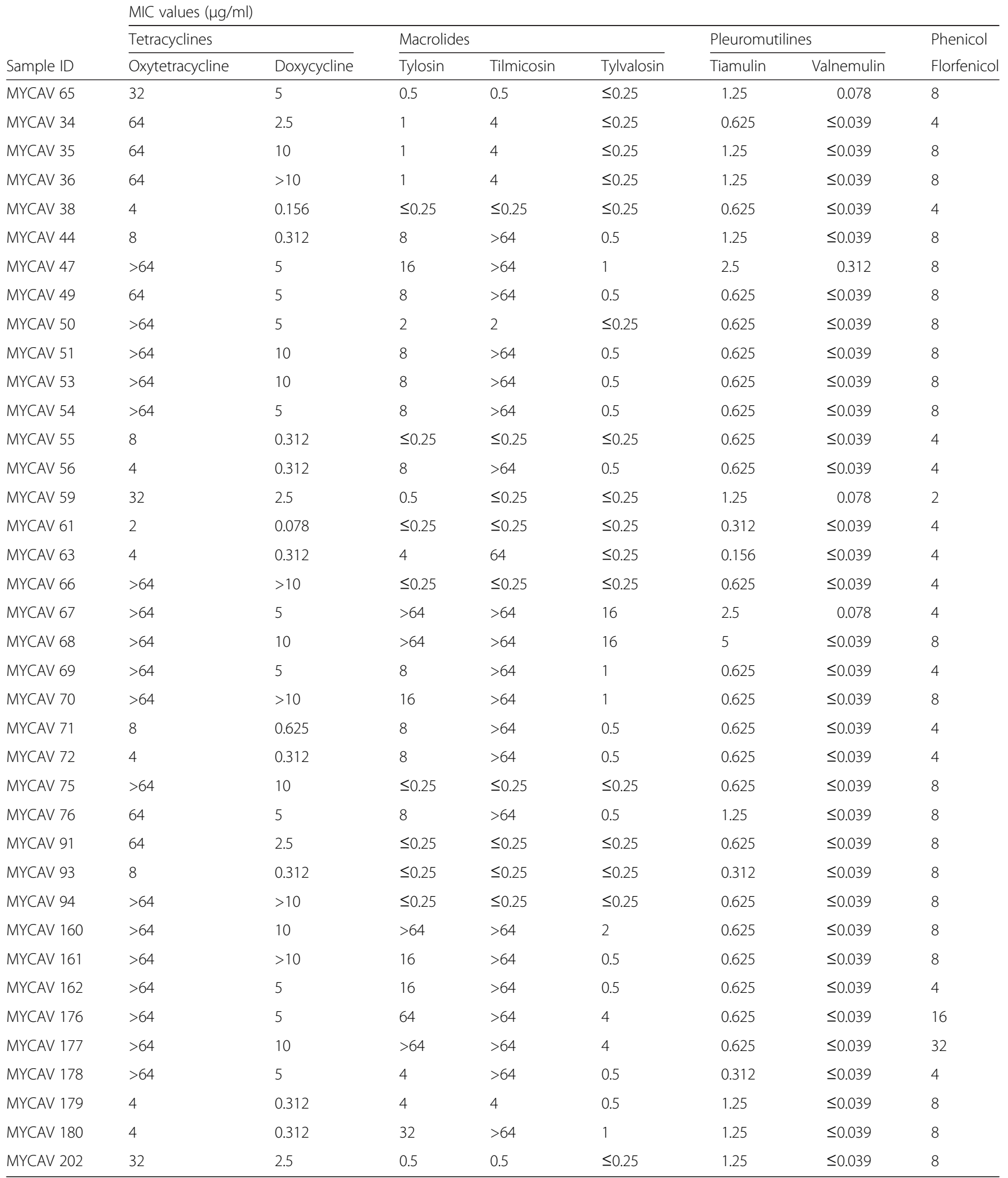

$>10 \mu \mathrm{g} / \mathrm{ml}$ ), while all strains had very high MIC values for norfloxacin $(\geq 10 \mu \mathrm{g} / \mathrm{ml})$ (Fig. 2a, b and c). The $\mathrm{MIC}_{50}$ was $8 \mu \mathrm{g} / \mathrm{ml}$ for spectinomycin and most of the strains yielded the $\mathrm{MIC}_{50}$ or higher MIC values (Fig. 2d). The MICs for lincomycin clustered around the $\mathrm{MIC}_{50}$ value $(4 \mu \mathrm{g} / \mathrm{ml})$ as well, but high MIC values $(>64 \mu \mathrm{g} / \mathrm{ml})$ were yielded in the case of three isolates (Fig. 2e). The $\mathrm{MIC}_{50}$ and the $\mathrm{MIC}_{90}$ values $(4 \mu \mathrm{g} / \mathrm{ml})$ for lincomycinspectinomycin (1:2) combination was the same as the $\mathrm{MIC}_{50}$ value for lincomycin. In the case of lincomycin- 


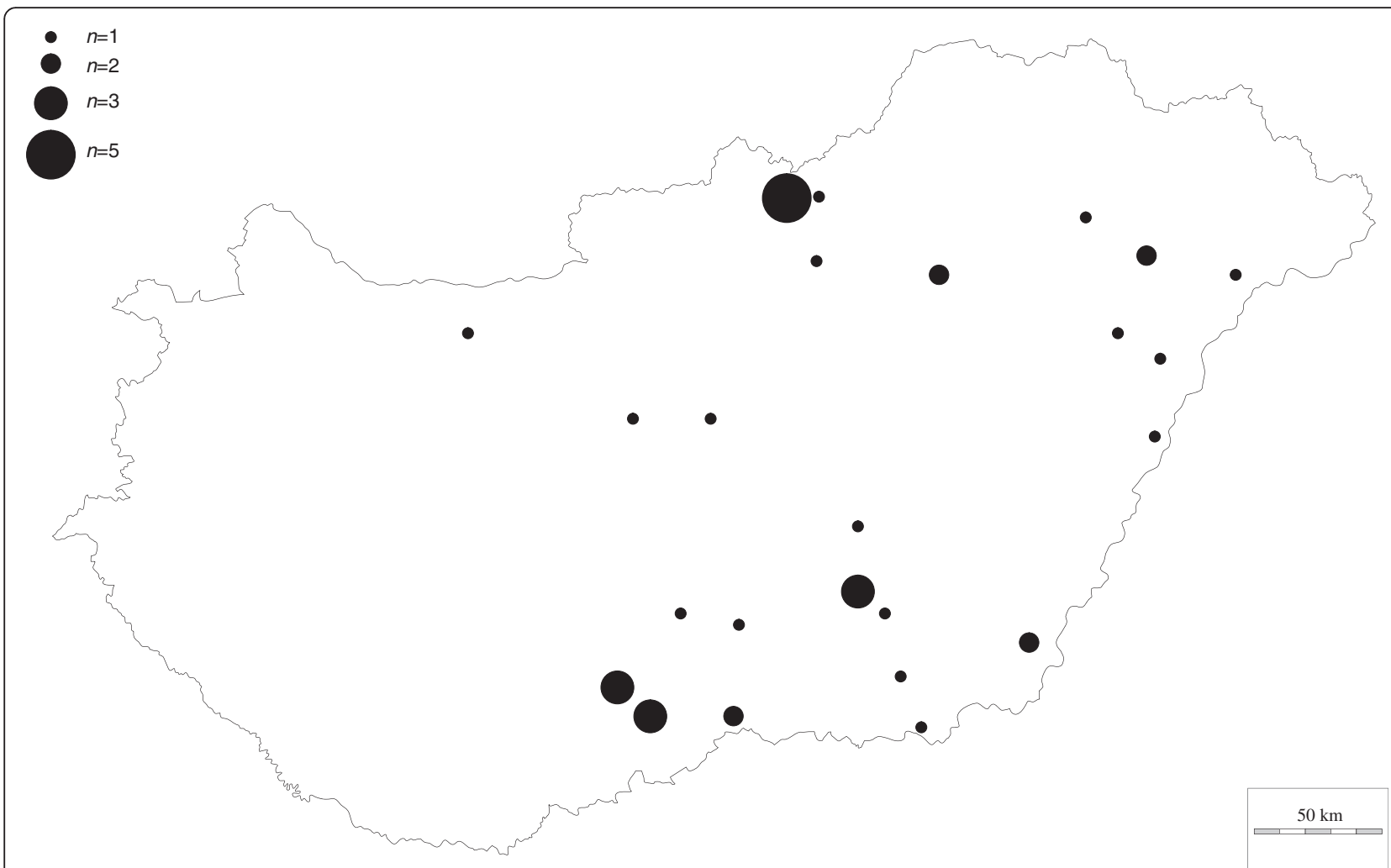

Fig. 1 Map of Hungary showing the geographical origin of the Mycoplasma sp. 1220 isolates. Size of the circles indicates the number ( $n$ ) of the strains. (The blank map was downloaded from an open source [28])

Table 2 Summary of MIC range, $\mathrm{MIC}_{50}$ and $\mathrm{MIC}_{90}$ values of the isolated Mycoplasma sp. 1220 strains

\begin{tabular}{|c|c|c|c|c|}
\hline Antibiotic class & Antibiotic agent & Range & $\mathrm{MIC}_{50}$ & $\mathrm{MIC}_{90}$ \\
\hline \multirow[t]{3}{*}{ Fluoroquinolones } & Enrofloxacin & 1.25 to $>10$ & 5 & $>10$ \\
\hline & Norfloxacin & 10 to $>10$ & $>10$ & $>10$ \\
\hline & Difloxacin & 1.25 to $>10$ & 10 & $>10$ \\
\hline Aminoglycoside & Spectinomycin & 4 to $>64$ & 8 & 32 \\
\hline \multirow[t]{2}{*}{ Lincosamide } & Lincomycin & 2 to $>64$ & 4 & 8 \\
\hline & $\begin{array}{l}\text { Lincomycin- } \\
\text { spectinomycin (1:2) } \\
\text { combination }\end{array}$ & 2 to 32 & 4 & 4 \\
\hline \multirow[t]{2}{*}{ Tetracyclines } & Oxytetracycline & 2 to $>64$ & 64 & $>64$ \\
\hline & Doxycycline & 0.078 to $>10$ & 5 & $>10$ \\
\hline \multirow[t]{3}{*}{ Macrolides } & Tylosin & $\leq 0.25$ to $>64$ & 8 & $>64$ \\
\hline & Tilmicosin & $\leq 0.25$ to $>64$ & $>64$ & $>64$ \\
\hline & Tylvalosin & $\leq 0.25$ to 16 & 0.5 & 4 \\
\hline \multirow[t]{2}{*}{ Pleuromutilins } & Tiamulin & 0.156 to 5 & 0.625 & 1.25 \\
\hline & Valnemulin & $\leq 0.039$ to 0.312 & $\leq 0.039$ & 0.078 \\
\hline Phenicol & Florfenicol & 2 to 32 & 8 & 8 \\
\hline
\end{tabular}

spectinomycin (1:2) combination the highest concentration needed for inhibition was $32 \mu \mathrm{g} / \mathrm{ml}$ (Fig. 2f). Broad ranges of the MIC values were observed for tetracyclines (2 to $>64 \mu \mathrm{g} / \mathrm{ml}$ for oxytetracycline and 0.078 to $>10 \mu \mathrm{g} / \mathrm{ml}$ for doxycycline) with high $\mathrm{MIC}_{50}$ and $\mathrm{MIC}_{90}$ values (Fig. $2 \mathrm{~g}$ and $\mathrm{h}$ ). The broadest ranges of MIC values were detected for tylosin and tilmicosin $(\leq 0.25$ to $>64 \mu \mathrm{g} / \mathrm{ml})$ with high $\mathrm{MIC}_{50}$ and $\mathrm{MIC}_{90}$ values in the case of tilmicosin (Fig. $2 \mathrm{i}$ and $\mathrm{j}$ ). While the MIC values for tylosin showed diverse distribution, the strains' susceptibility profiles formed three groups in the case of tilmicosin $(\leq 0.25,4$ and $>64 \mu \mathrm{g} / \mathrm{ml})$ (Fig. 2j). Among the examined three macrolides (tylosin, tilmicosin and tylvalosin), tylvalosin showed the lowest $\mathrm{MIC}_{50}$ value $(0.5 \mu \mathrm{g} / \mathrm{ml})$ against the strains (Fig. $\left.2 \mathrm{k}\right)$. From the pleuromutilins the MIC values of tiamulin were higher than those of valnemulin, and the latter compound was found to be the most active antibiotic in the examinations (Fig. $2 \mathrm{l}$ and $\mathrm{m}$ ). In the case of florfenicol, the susceptibility profiles of most strains were similar to each other and showed the $\mathrm{MIC}_{50}$ and $\mathrm{MIC}_{90}$ value $(8 \mu \mathrm{g} / \mathrm{ml})$ or its twofold lower dilution $(4 \mu \mathrm{g} / \mathrm{ml})$ with few exceptions (Fig. $2 \mathrm{n}$ ).

$M$. sp. 1220 strains isolated year by year from the same farms and from the same tissue types (e.g. strains MYCAV 34, 53 and 67 from Szentes, strains MYCAV 50, 70, 176 and 177 from Cered, or strains MYCAV 38 and 202 from Kelebia) showed elevated MIC values from 

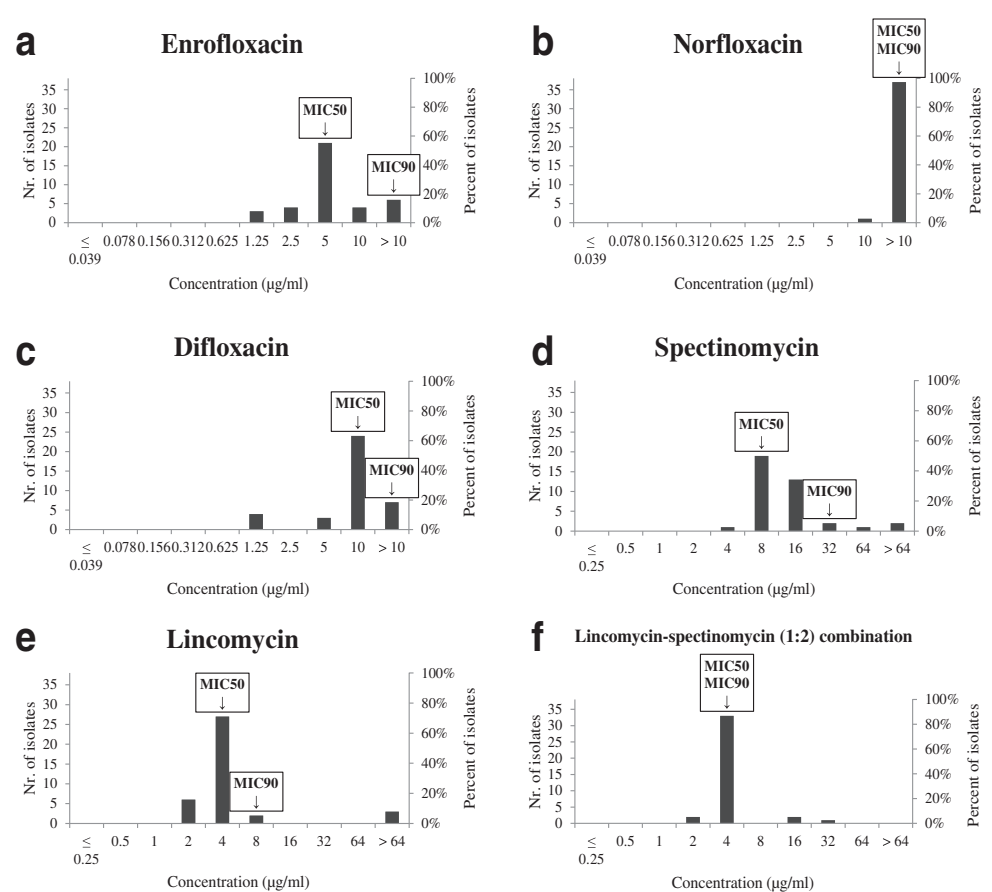

f Lincomycin-spectinomycin (1:2) combination
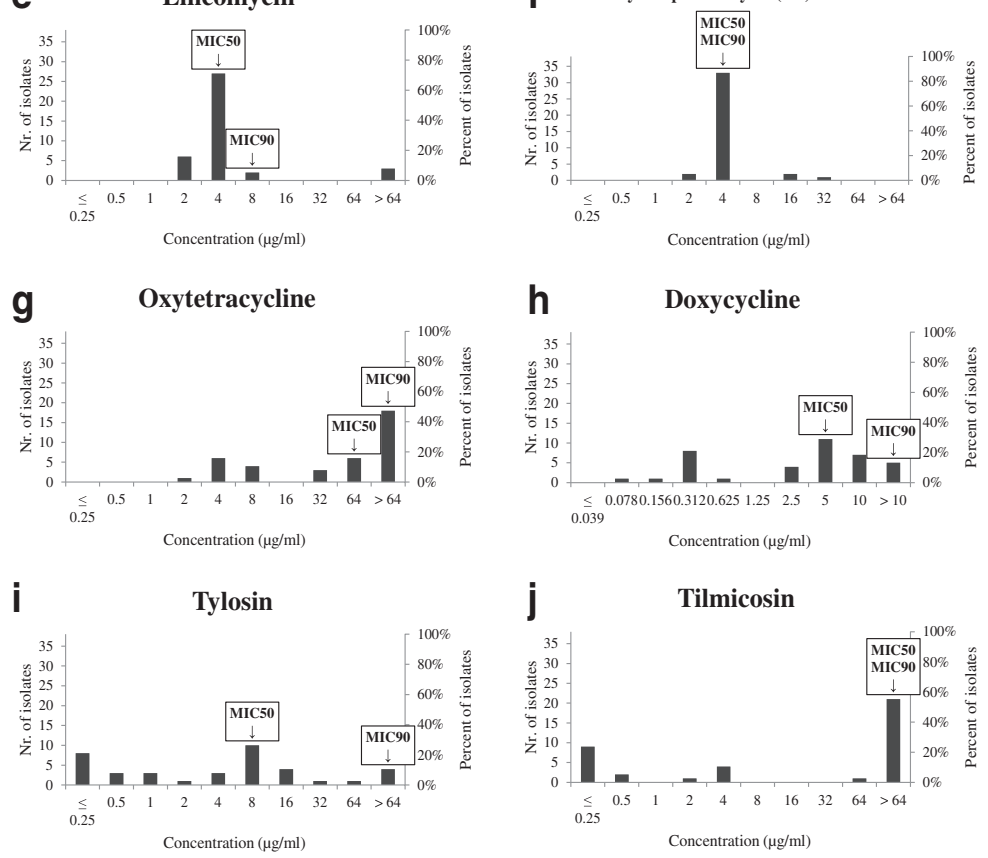

$\mathbf{k}$

Tylvalosin
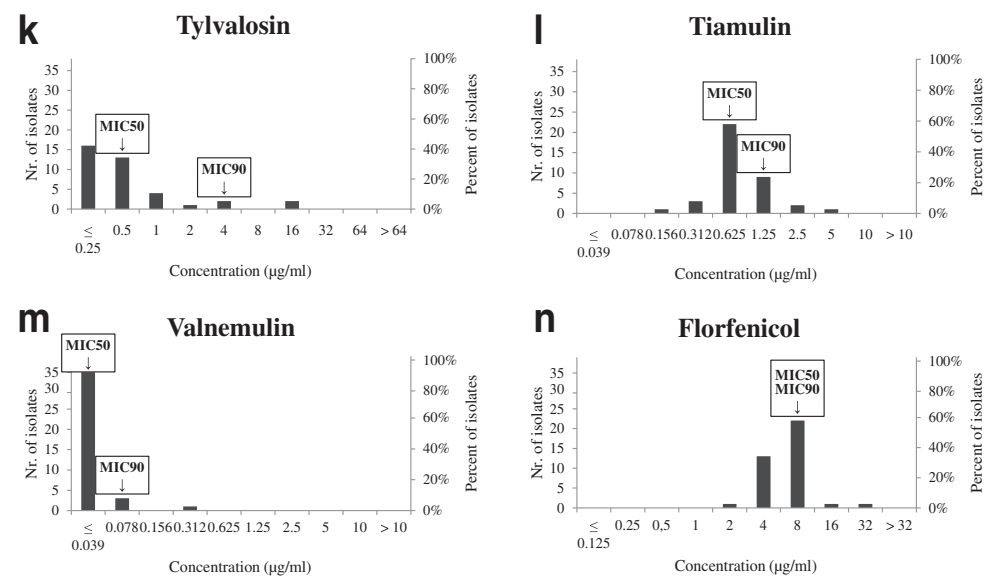

n Florfenicol

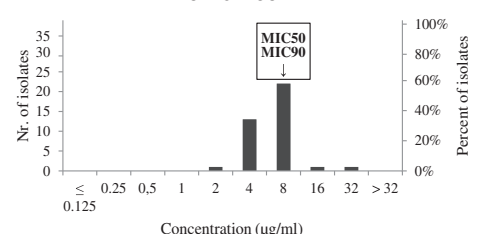

Fig. 2 MIC distribution of test antibiotics against Mycoplasma sp. 1220 isolates 
year to year in the cases of certain antibiotics. Higher MIC values were detected in subsequent isolates for lincomycin, lincomycin-spectinomycin combination, tetracyclines (both oxytetracycline and doxycycline), macrolides (tylosin, tilmicosin and tylvalosin), tiamulin and for florfenicol as well.

\section{Discussion}

Information about the susceptibility of $M$. sp. 1220 strains to antimicrobials is scarce, as until to date the sole published reference concerning the antibiotic susceptibility profile of this species is a review of Stipkovits and Szathmary [3]. Stipkovits and Szathmary determined the values of enrofloxacin, tylosin, chlortetracycline, oxytetracycline, doxycycline, tiamulin and lincomycin in Mycoplasma species affecting waterfowl ( $M$. anatis, $M$. cloacale, $M$. anseris and $M$. sp. 1220), although detailed data of their method is lacking [3]. Thus we are facing the absence of reports about the antibiotic susceptibility of $M$. sp. 1220 and also of other Mycoplasma species occurring in waterfowl. Therefore, the results of the current study are also compared to data of antibiotic susceptibility of the wellstudied Mycoplasma species of poultry: M. synoviae and M. gallisepticum.

Elevated MIC values were reported previously in the case of the fluoroquinolones, especially of enrofloxacin in $M$. sp. $1220\left(\mathrm{MIC}_{50} 2 \mu \mathrm{g} / \mathrm{ml}\right.$ and $\left.\mathrm{MIC}_{90} 4 \mu \mathrm{g} / \mathrm{ml}\right)$ and other Mycoplasma species of poultry [3, 13, 20, 21]. In addition, the increasing occurrence of quinoloneresistant M. synoviae and M. gallisepticum field isolates were also observed $[13,22]$. In the current study, the detected $\mathrm{MIC}_{50}$ values $(5 \mu \mathrm{g} / \mathrm{ml}$ for enrofloxacin, $10 \mu \mathrm{g} / \mathrm{ml}$ for difloxacin and $\geq 10 \mu \mathrm{g} / \mathrm{ml}$ for norfloxacin) were even higher than the ones reported before [3, 13, 20-22], confirming the observation of increasing quinolone-resistance in Mycoplasma species. In order to save these antibiotics for human disease treatment the directive was to reduce the use of these agents in livestock. Former efforts for the prevention of the appearance of quinolone-resistant species are proved to be unsuccessful considering the observed dramatic elevations in the MIC values of these antibiotics in avian Mycoplasma species [13, 21, 23].

Administration of the combination of lincomycin and spectinomycin could reduce the egg infertility rates and increase the hatching rates and the egg production in M. sp. 1220 infected geese [11]. The lincomycinspectinomycin therapy was proved to be effective against other Mycoplasma species as well; however, application of spectinomycin in monotherapy is not recommended for its insufficient effectiveness and relatively high MIC values in in vitro experiments [12]. In vitro effectiveness of lincomycin at $2 \mu \mathrm{g} / \mathrm{ml} \mathrm{MIC}_{50}$ values against $M$. sp. 1220, $M$. anseris and $M$. anatis species has been reported [3]. In the present study, all isolates showed elevated MIC values for spectinomycin, lincomycin and lincomycin-spectinomycin combination. The growth of a couple of strains was not inhibited even at the highest concentrations used $(64 \mu \mathrm{g} / \mathrm{ml})$ for spectinomycin and lincomycin individually. The combination of the two antibiotics improved their effectiveness, as lincomycin-spectinomycin combination could inhibit the growth of all examined strains within the concentration range used $(0.25$ to $64 \mu \mathrm{g} / \mathrm{ml})$ and lower $\mathrm{MIC}_{90}$ value was observed also.

Previously, tetracyclines (chlortetracycline, doxycycline and oxytetracycline) showed $1-2 \mu \mathrm{g} / \mathrm{ml}$ MIC values against M. sp. 1220 strains. Growth of other Mycoplasma species isolated from waterfowl were inhibited at $2-4 \mu \mathrm{g} / \mathrm{ml}$ $\mathrm{MIC}_{50}$ values using the same antibiotics [3]. Previously Mycoplasma species infecting poultry were observed to be inhibited by elevated MIC values, although with exceptions, as $M$. synoviae strains showed high susceptibility to doxycycline in the Netherlands [12-14]. In the current study, although the M. sp. 1220 strains showed broad ranges of MIC values for oxytetracycline and doxycycline, more than $50 \%$ of the strains were inhibited by only higher antibiotic concentrations (64 and $5 \mu \mathrm{g} / \mathrm{ml}$, respectively) and $\mathrm{MIC}_{90}$ values exceeded the concentration ranges used for both compounds. These results show a dramatic increase of the MIC values of tetracyclines against $M$. sp. 1220 strains and reveals the presence of probably highly resistant strains in Hungary.

Macrolides, especially tylvalosin have good in vitro effectiveness against most Mycoplasma species infecting poultry, showing lower MIC values in previous examinations than quinolones and tetracyclines [3, 12-15]. However, $M$. gallisepticum could develop resistance rapidly to these compounds, especially to tilmicosin [24]. Earlier, the $\mathrm{MIC}_{50}$ values in $M$. sp. 1220, M. anatis, M. anseris and $M$. cloacale strains were defined to be $2 \mu \mathrm{g} / \mathrm{ml}$ for tylosin [3]. In the current study, the $\mathrm{MIC}_{50}$ value $(8 \mu \mathrm{g} /$ $\mathrm{ml}$ ) of tylosin was higher than the previous observation [3], and the $\mathrm{MIC}_{90}$ value exceeded the concentration range used in the experiment. However, high variability was observed in the susceptibility of the strains to this compound. Similarly, wide range of the MIC values was detected for tilmicosin, highlighting the necessity of susceptibility testing before antibiotic treatments. As opposed to the diverse susceptibility profiles of the strains for tylosin, the MIC values of tilmicosin were categorized into three separate groups. The observed distribution of the MIC values is likely in association with the capability of Mycoplasma sp. 1220 to develop resistance more rapidly to tilmicosin (i.e. with one or two mutations) than to other macrolides. The same phenomenon was described in other Mycoplasma species as well [24]. Out of the three macrolides examined in the study, tylvalosin proved to be the most effective agent against $M$. sp. 1220 strains, showing lower $\mathrm{MIC}_{50}$ value 
$(0.5 \mu \mathrm{g} / \mathrm{ml})$ against the pathogen than the majority of the antibiotics tested.

Pleuromutilins showed good in vitro effectiveness against avian Mycoplasma species in previous studies and low tendency of the development of resistance to these agents has been reported [16-18, 21]. Tiamulin was used successfully for the treatment of mycoplasmosis and its effectiveness was similar to spectinomycin therapy in the treated geese [11]. Stipkovits and Szathmary described low MIC values $\left(\mathrm{MIC}_{50}: 0.06 \mu \mathrm{g} / \mathrm{ml}\right.$, $\mathrm{MIC}_{90}: 0.25 \mu \mathrm{g} / \mathrm{ml}$ ) of tiamulin in the case of $M$. sp. 1220 , and similarly low $\mathrm{MIC}_{50}$ values $(0.125-1 \mu \mathrm{g} / \mathrm{ml})$ were observed against $M$. anseris, $M$. anatis and $M$. cloacale [3]. In the present study, pleuromutilins were found to be the most effective antibiotic agents and the examined compounds, especially valnemulin showed high in vitro effectiveness against all tested isolates of the pathogen. However, it is noteworthy, that strains with elevated MIC values were detected for tiamulin (MIC: $2.5-5 \mu \mathrm{g} / \mathrm{ml}$ ) and even for valnemulin (MIC: $0.312 \mu \mathrm{g} / \mathrm{ml})$. Although the low MIC values of valnemulin against $M$. sp. 1220 strains in vitro are promising for its clinical use, it should be noted that in a previous study only a single mutation in M. gallisepticum could cause elevation in the MIC values of valnemulin [17]. To date, the use of pleuromutilins in humans is limited, as only one commercially available product is authorized containing this active substance. However, bacterial strains resistant to pleuromutilins have already been described and these strains also show multidrug resistance, which warrants the prudent use of these antibiotic agents [25].

Phenicols showed good in vitro activity against Mycoplasma species of poultry, but information about their effectiveness in waterfowl is lacking [26, 27]. In the present study, most of the $M$. sp. 1220 isolates yielded the same MIC values $(4 \mathrm{or} 8 \mu \mathrm{g} / \mathrm{ml}$ ) for florfenicol, and only two isolates (originating from the same region) showed elevated MIC values compared to the $\mathrm{MIC}_{50}$ $(8 \mu \mathrm{g} / \mathrm{ml})$, one of them reaching the highest antibiotic concentration $(32 \mu \mathrm{g} / \mathrm{ml})$ used.

The elevated MIC values of several antibiotics detected in subsequent isolates from the same farms from year to year are likely in association with the inconsistent use of antibiotics, the rapid development of antibiotic resistance and highlight the importance of susceptibility testing before therapy and responsible use of antimicrobial drugs.

\section{Conclusion}

In the present examinations the antibiotic susceptibility profiles of thirty-eight $M$. sp. 1220 strains isolated in Hungary were determined. To the best of our knowledge, this is the first detailed study about the antibiotic susceptibility of $M$. sp. 1220 , a pathogen which could cause significant economic losses in waterfowl flocks. Valnemulin, tiamulin and tylvalosin were found to be the most effective antibiotics in the present study. Most of the isolates showed elevated MIC values for more than one agent, but none of the strains yielded high MIC values for all the examined antibiotics. Nevertheless, our results confirmed that increasing resistance could be observed in the cases of several antibiotics. These findings highlight the consistent use of antibiotics and the need for determination of antibiotic susceptibility of Mycoplasma species before treatment.

\section{Funding \\ This work was supported by the Lendület (Momentum) programme (LP2012-22) of the Hungarian Academy of Sciences. The funders had no role in study design, data collection, analysis and interpretation, decision to publish, or preparation of the manuscript.}

Availability of data and materials

All data supporting the findings is contained within the manuscript.

\section{Authors' contributions}

All authors read and approved the final manuscript. DG, ZK and KMS analysed the data and wrote the manuscript. DG and $\mathrm{VH}$ performed the examinations. ZR, IT and SJ collected the samples, isolated the strains and edited the manuscript. MG designed the study, analysed the data and edited the manuscript.

\section{Competing interests}

The authors declare that they have no competing interests.

\section{Consent for publication}

Not applicable.

\section{Ethics approval and consent to participate}

The ethics committees of the Institute for Veterinary Medical Research ruled that no formal ethics approval or consent were required as the samples were collected during routine diagnostic examinations or necropsies.

\section{Author details}

${ }^{1}$ Institute for Veterinary Medical Research, Centre for Agricultural Research, Hungarian Academy of Sciences, Hungária körút 21, Budapest 1143, Hungary. ${ }^{2}$ Veterinary Diagnostic Directorate, National Food Chain Safety Office, P.O. Box 21581, Budapest, Hungary.

Received: 2 March 2016 Accepted: 10 August 2016

Published online: 19 August 2016

\section{References}

1. Stipkovits L, Varga Z, Czifra G, Dobos-Kovacs M. Occurrence of mycoplasmas in geese affected with inflammation of the cloaca and phallus. Avian Pathol. 1986;15:289-99.

2. Stipkovits L, Kempf I. Mycoplasmoses in poultry. Rev Sci Tech. 1996; 15:1495-525.

3. Stipkovits L, Szathmary S. Mycoplasma infection of ducks and geese. Poult Sci. 2012;91:2812-9.

4. Stipkovits L, Varga Z, Glavits R, Ratz F, Molnar E. Pathological and immunological studies on goose embryos and one-day-old goslings experimentally infected with a Mycoplasma strain of goose origin. Avian Pathol. 1987;16:453-68.

5. Dobos-Kovacs M, Varga Z, Czifra G, Stipkovits L. Salpingitis in geese associated with Mycoplasma sp. strain 1220. Avian Pathol. 2009;38:239-43.

6. Hinz K-H, Pfützner H, Behr K-P. Isolation of mycoplasmas from clinically healthy adult breeding geese in germany. J Vet Med B. 1994;41:145-7.

7. Jordan FT, Gilbert S, Knight DL, Yavari $C$ a. Effects of baytril, tylosin and tiamulin on avian mycoplasmas. Avian Pathol. 1989;18:659-73.

8. Stipkovits L, Glavits R, Ivanics E, Szabo E. Additional data on Mycoplasma disease of goslings. Avian Pathol. 1993;22:171-6. 
9. Hannan PCT. Guidelines and recommendations for antimicrobial minimum inhibitory concentration (MIC) testing against veterinary mycoplasma species. Vet Res. 2000;31:373-95.

10. Stipkovits L, Varga Z, Dobos-Kovacs M, Santha M. Biochemical and serological examination of some Mycoplasma strains of goose origin. Acta Vet Hung. 1984;32:117-25.

11. Czifra G, Varga Z, Dobos-Kovacs M, Stipkovits L. Medication of inflammation of the phallus in geese. Acta Vet Hung. 1986;34:211-23.

12. Behbahan NGG, Asasi K, Afsharifar AR, Pourbakhsh SA. Susceptibilities of Mycoplasma gallispeticum and Mycoplasma synoviae Isolates to Antimicrobial Agents in vitro. Int J Poult Sci. 2008;7:1058-1064.

13. Landman WJ, Mevius DJ, Veldman KT, Feberwee A. In vitro antibiotic susceptibility of Dutch Mycoplasma synoviae field isolates originating from joint lesions and the respiratory tract of commercial poultry. Avian Pathol. 2008:37:415-20

14. Wang C, Ewing M, Aarabi SY. In vitro susceptibility of avian mycoplasmas to enrofloxacin, sarafloxacin, tylosin, and oxytetracycline. Avian Dis. 2001;45:456-60

15. Forrester CA, Bradbury JM, Dare CM, Domangue RJ, Windsor H, Tasker JB, Mockett APA. Mycoplasma gallisepticum in pheasants and the efficacy of tylvalosin to treat the disease. Avian Pathol. 2011;40:581-6.

16. Drews J, Georgopoulos A, Laber G, Shütze E, Unger J. Antimicrobial Activities of $81.723 \mathrm{hfu}$, a New Pleuromutilin Derivative. Antimicrob Agent Chemother. 1975;7:507-516.

17. Li B-B, Shen J-Z, Cao X-Y, Wang Y, Dai L, Huang S-Y, Wu C-M. Mutations in 23S rRNA gene associated with decreased susceptibility to tiamulin and valnemulin in Mycoplasma gallisepticum. FEMS Microbiol Lett. 2010;308:144-9.

18. Xiao X, Sun J, Chen Y, Zou M, Zhao D-H, Liu Y-H. Ex vivo pharmacokinetic and pharmacodynamic analysis of valnemulin against Mycoplasma gallisepticum S6 in Mycoplasma gallisepticum and Escherichia coli coinfected chickens. Vet J. 2015;204:54-9.

19. Lauerman LH, Chilina AR, Closser JA, Johansen D. Avian mycoplasma identification using polymerase chain reaction amplicon and restriction fragment length polymorphism analysis. Avian Dis. 1995;39:804-11.

20. Lysnyansky I, Gerchman I, Mikula I, Gobbo F, Catania S, Levisohn S. Molecular characterization of acquired enrofloxacin resistance in Mycoplasma synoviae field isolates. Antimicrob Agents Chemother. 2013;57:3072-7.

21. Gautier-Bouchardon AV, Reinhardt AK, Kobisch M, Kempf I. In vitro development of resistance to enrofloxacin, erythromycin, tylosin, tiamulin and oxytetracycline in Mycoplasma gallisepticum, Mycoplasma iowae and Mycoplasma synoviae. Vet Microbiol. 2002;88:47-58.

22. Gerchman I, Lysnyansky I, Perk S, Levisohn S. In vitro susceptibilities to fluoroquinolones in current and archived Mycoplasma gallisepticum and Mycoplasma synoviae isolates from meat-type turkeys. Vet Microbiol. 2008;131:266-76.

23. European Medicines Agency, EMA/186029/2010. [http://www.ema.europa. eu/docs/en_GB/document_library/Referrals_document/quinolones_35/ WC500094630.pdf]. Accessed 11 Nov 2015.

24. Wu CM, Wu H, Ning Y, Wang J, Du X, Shen J. Induction of macrolide resistance in Mycoplasma gallisepticum in vitro and its resistancerelated mutations within domain $V$ of $23 S$ rRNA. FEMS Microbiol Lett. 2005;247:199-205

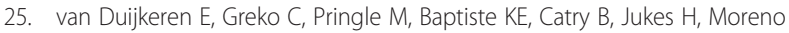
MA, Pomba MCMF, Pyorala S, Rantala M, Ru auskas M, Sanders P, Teale C, Threlfall EJ, Torren-Edo J, Torneke K. Pleuromutilins: use in food-producing animals in the European Union, development of resistance and impact on human and animal health. J Antimicrob Chemother. 2014;69:2022-31.

26. Gharaibeh S, Al-Rashdan M. Change in antimicrobial susceptibility of Mycoplasma gallisepticum field isolates. Vet Microbiol. 2011;150:379-83.

27. Lin MY. In vitro comparison of the activity of various antibiotics and drugs against New taiwan isolates and standard strains of avian mycoplasma. Avian Dis. 1987;31:705-12.

28. Hungary outline. [http://d-maps.com/carte.php?num_car=23243\&lang=en] Accessed 10 Aug 2015

\section{Submit your next manuscript to BioMed Central and we will help you at every step:}

- We accept pre-submission inquiries

- Our selector tool helps you to find the most relevant journal

- We provide round the clock customer support

- Convenient online submission

- Thorough peer review

- Inclusion in PubMed and all major indexing services

- Maximum visibility for your research

Submit your manuscript at www.biomedcentral.com/submit
Biomed Central 